\title{
EDITORIAL
}

\section{Triage and ATS: Collateral damage in the quest to improve ED performance}

Australia is a world leader in the development and validation of triage scales. The National Triage Scale (NTS) was introduced in 1993, later becoming the Australasian Triage Scale (ATS) in $2000^{1,2}$ effecting a nationally consistent approach to ED triage with descriptors on maximum acceptable waiting times for patients. Both the NTS and ATS have well validated and have formed the basis of other triage systems in use internationally. ${ }^{3}$ Standardised triage systems optimise patient safety in the face of excessive demand for services, afford efficiency of ED services, and ensure equity of access to health services across the population. ${ }^{4}$ The practise of triage including application of the ATS is underpinned by: (i) a robust body of research demonstrating its efficacy, and (ii) a national triage education program based on a systematic approach to patient assessment and evidence-based discriminators for ATS application to adults (including pregnant women), children and also patients suffering from mental health issues, pain, and ophthalmic emergencies. ${ }^{4}$ Both leading professional emergency care colleges in Australia, the College of Emergency Nursing Australasia and the Australasian College for Emergency Medicine, maintain that the ATS is a valid tool for prioritisation of patients and their emergency care according to clinical urgency. ${ }^{3,5}$

Like many other countries, Australian EDs are struggling with increasing demand for emergency healthcare services, ${ }^{6,7}$ overcrowding and access block. ${ }^{8-12}$ In an attempt to enhance quality of care by improving ED performance, the Australian Government implemented the National Emergency Access Target (NEAT) or 'four hour rule'. ${ }^{13,14}$ In implementing NEAT, ED triage has come under intense criticism and scrutiny with calls for it to be abolished or at least modified.

One modification calls to replace the ED nurse triage with a system where arriving patients are assessed within minutes by a 'staff member' capable of initiating and managing their care. ${ }^{15}$ Under this system, patients will require allocation to an area within the ED where staffing skill mix and resources match their clinical urgency so there will still be a triage process, however termed. ${ }^{15}$ Proponents of this model suggest that ED triage in its entirety results in "nursing staff categorising the relative urgency of patient care rather than initiating treatment'.${ }^{15}$ The authors do acknowledge that triage is a "necessary response to a crowded waiting room and is aimed at safely managing a delay," ${ }^{15}$ but we argue this view fails to recognise that both initial assessment of clinical urgency and secondary triage decisions that decrease time to care, investigations, symptom relief, and promotion of comfort ${ }^{17,18}$ constitutes treatment. The Australian Institute for Health and Welfare (AlHW) data suggests that there is still work needed to achieve "wait free" emergency care. In 2010-11, 70\% of patients were seen within the recommended time for their triage category ${ }^{6}$ leaving over 1.8 million Australian ED patients in the care of triage and emergency nurses whilst waiting for further treatment.

Another view is that ATS Category 1 and 2 patients should be seen immediately and ATS category 3, 4 and 5 patients in order of arrival, rather than within the existing time periods associated with each category. ${ }^{16-18}$ Proponents of this have claimed to have trialing such a model, which they argue "has improved access to care and reduced overall waiting times...without compromising the care of the critically ill" 16 and that use of the ATS to prioritize the order in which patients were seen extends the ED length of stay. ${ }^{17}$ It appears that in this instance the ATS was still used and that the intervention tested at a single health service was in fact the streaming of patients according to likely admission or discharge rather than an alternative of triage model. ${ }^{17}$ In Australia, 21\% of ATS 2 patients wait longer than $10 \mathrm{~min}$ for emergency care $^{6}$ and so simply changing the triage scale to recommend that these patients are seen "immediately" will not in our view correct this related but fundamental problem of ED performance rather than triage. Further, management of ATS 3, 4 and 5 patients in arrival order raises risk management and ethical issues. Seeing patients with pain after patients without pain is unethical and seeing patients with normal physiology before patients with abnormal physiology presents unjustifiable risks to 
patient care and is poor clinical risk management. Given the clear relationship between abnormal vital signs and serious in-hospital adverse events (death, cardiac arrest and unplanned intensive care admission), ${ }^{19-26}$ this practice directly contradicts the overwhelming mandate for quality and safety in health care, and we would suggest leave EDs and practitioners open to indefensible medico-legal liability in the case of an adverse outcome.

Calls to modify the ATS and triage practice and the arguments that underpin them persist despite clear evidence that: (i) the ATS is valid and reliable ${ }^{3}$ and (ii) clinician decision performance using validated decision support tools is superior to using unaided judgment or tools that do not have appropriate validated performance. ${ }^{27}$ Of the five-level triage scales currently in use globally, the ATS has a higher level of inter-rater reliability agreement than the Canadian Triage and Acuity Scale and Manchester Triage Scale (median $\kappa=0.54,0.52$ and 0.33 respectively). ${ }^{28}$ The only study comparing three and five-level triage scales showed that five-level scales have increased levels of agreement, discrimination, sensitivity and specificity, and decreased rates of under-triage. ${ }^{29}$ Comparison of reliability measures (kappa statistics: $\kappa$ ) further supports that five-level triage scales are more reliable than three and four-level scales. The $\kappa$ value for five-level scales ranges from 0.38 (fair) to 1.0 (very good) compared to 0.19 (poor) to 0.53 (moderate) for three and four-level scales. ${ }^{28}$ Criticisms of the ATS and its performance quite simply do not square with this evidence.

In our view, calls to abandon the ATS occur without any published evidence that the ATS is no longer valid or reliable and with no validated alternative approach to ED triage, are ill-conceived, and the arguments promulgated to justify them are unsubstantiated. The problems of ED and hospital performance, namely waiting times, ED length of stay, ambulance bypass, patient throughput and access block, have been inappropriately attributed to the ATS. Prolonged waiting times are a function of inadequate ED performance. ED overcrowding and length of stay are markers of ED and health service performance rather than indicators of the effectiveness of the ATS. Failure to meet these performance standards have resulted in calls to reject the widely validated triage tool, ATS, in favour of the alternatives outlined earlier, all of which lack a robust evidence-base. If there were calls to change other validated emergency care tools such as NEXUS, ${ }^{30}$ the Canadian cervical spine rules ${ }^{31,32}$ or Ottawa Ankle rules ${ }^{33-35}$ or purposefully deviate from evidence-based best practice, there would be professional outcry.

The real question is not whether triage, and specifically application of the ATS, is appropriate but rather what happens to patients once they have been triaged. Nothing in adherence to the ATS would prevent creative means of fast tracking or streaming of patients in larger EDs, nor prevent innovative approaches to rapid initiation of advanced resuscitation; including nurse initiated investigation and treatment. This rejection of the ATS is both unnecessary and illogical and results from confusion between the ATS as a tool and the ED performance standards that have been linked to it. The real solution lies in developing and validating ED performance standards that are reasonable and achievable, and properly resourcing health services to achieve those standards. Triage nurses have a professional responsibility to critically examine calls to change triage practice against the current evidence base, and rather than blindly agree with alternative triage systems, demand evidence of their reliability, validity and safety prior to implementation in clinical practice.

Julie Considine, RN, PhD, FACN, FCENA* Deputy Editor, Australasian Emergency Nursing Journal, Associate Professor, School of Nursing and Midwifery, Deakin University, Burwood, Victoria, Australia

Ramon Z. Shaban, RN, PhD, FACN, FCENA Editor-in-Chief, Australasian Emergency Nursing Journal, Associate Professor, Griffith Heath Institute Research Centre for Clinical and Community, Practice Innovation, Griffith University, Australia

Gerard J. FitzGerald, MBBS, MD, FACEM Professor of Public Health, School of Public Health, Queensland University of Technology, Kelvin Grove,

Queensland, Australia

Shane Thomas, BA, PhD, DipPubPol School of Primary Health Care, Monas University, Clayton, Victoria, Australia

Colin A. Graham, MD, MPH, FCEM, FHKCEM Editor-in-Chief, European Journal of Emergency Medicine, Professor, Accident and Emergency Medicine Academic Unit, Chinese University of Hong Kong, Hong Kong

* Corresponding author. Tel.: +61 0392446127 ; fax: +610392446159.

E-mail address: julie.considine@deakin.edu.au (J. Considine)

10 September 2012

\section{References}

1. Australasian College for Emergency Medicine. Policy Document: The Australasian Triage Scale. Retrieved 2 June 2010 from http://www.acem.org.au/media/policies_and_guidelines/P06_ Aust_Triage_Scale_Nov_2000.pdf; 2000 (reviewed 2006).

2. Australasian College for Emergency Medicine. Guidelines on the Implementation of the Australasian Triage Scale in Emergency Departments. Retrieved 2 June 2010 from http://www.acem. org.au/media/policies_and_guidelines/G24_Implementation _ATS.pdf; 2000 (revised 2005).

3. Forero R, Nugus P. Australasian College for Emergency Medicine Literature Review on the Australasian Triage Scale (ATS). Sydney: University of New South Wales, Australian Institute of Health Innovation; 2012.

4. Gerdtz M, Considine J, Sands N, Stewart C, Crellin D, Pollock W, et al. Emergency Triage Education Kit. Canberra: Australian Government Department of Health and Ageing; 2007.

5. College of Emergency Nursing Australasia (CENA). Position Statement: Triage and the Australasian Triage Scale. Burwood, NSW: College of Emergency Nursing Australasia (CENA). Retrieved 17 July 2012 from http://cena.org. au/CENA/Documents/2012_06_14_CENA_Position_Statement_ Triage_FinalD2-1.pdf; 2012.

6. Australian Institute of Health and Welfare. Australian hospital statistics 2010-11: emergency department care and elective surgery waiting times. Canberra: Australian Institute of Health and Welfare. Health services series no. 
41. Cat. no. HSE 115. Retrieved 30 January 2012 from http: / / www.aihw.gov.au/publication-detail/?id=6442472405; 2011.

7. Lowthian JA, Curtis AJ, Jolley DJ, Stoelwinder JU, MCNeil JJ, Cameron PA. Demand at the emergency department front door: 10-year trends in presentations. Med J Aust 2012;196(2):128-32.

8. Asplin BR, Magid DJ, Rhodes KV, Solberg LI, Lurie N, Camargo Jr CA. A conceptual model of emergency department crowding. Ann Emerg Med 2003;42(2):173-80.

9. Derlet R. Overcrowding in emergency departments: increased demand and decreased capacity. Ann Emerg Med 2002;39:430-2.

10. Higginson I. Emergency department crowding. Emerg Med $\mathrm{J}$ 2012;29(6):437-43.

11. Pines JM, Hilton JA, Weber EJ, Alkemade AJ, Al Shabanah $\mathrm{H}$, Anderson PD, et al. International perspectives on emergency department crowding. Acad Emerg Med 2011;18(12): 1358-70.

12. Hoot NR, Aronsky D. Systematic review of emergency department crowding: causes, effects, and solutions. Ann Emerg Med 2008;52(2), 126-36.e1.

13. Geelhoed GC, de Klerk NH. Emergency department overcrowding, mortality and the 4-hour rule in Western Australia. Med $J$ Aust 2012;196(2):122-6.

14. Baggoley C, Owler B, Grigg $M$, Wellington $H$, Monaghan $M$, Hartley-Jones J. Expert Panel Review of Elective Surgery and Emergency Access Targets under the National Partnership Agreement on Improving Public Hospital Services. Canberra: Report to the Council of Australian Governments. Retrieved 20 June 2012 from http://www.coag. gov.au/docs/Expert_Panel_Report\%20D0490.pdf; 30 June 2011.

15. Newnham H, Smit PD, Keogh M, Strip M, Cameron P. Emergency and acute medical admissions: insights from US and UK visits by a Melbourne tertiary health service. Med J Aust 2012;196(2):101-3.

16. Ben-Tovim DI, Dougherty ML, O'Connell TJ, McGrath KM. Patient journeys: the process of clinical redesign. Med J Aust 2008;188(6):14.

17. King DL, Ben-Tovim DI, Bassham J. Redesigning emergency department patient flows: application of lean thinking to health care. Emerg Med Austral 2006;18(4): 391-7.

18. Ben-Tovim DI, Bassham JE, Bolch D, Martin MA, Dougherty M, Szwarcbord M. Lean thinking across a hospital: redesigning care at the Flinders Medical Centre. Aust Health Rev 2007;31(1):10-5.

19. A prelude to outreach: prevalence and mortality of ward patients with abnormal vital signs. In: 15th annual congress of the european society of intensive care medicine. Barcelona: Spain Intensive Care Medicine; 2002.

20. Bedell SE, Deitz DC, Leeman D, Delbanco TL. Incidence and characteristics of preventable iatrogenic cardiac arrests. JAMA 1991;265(21):2815-20.
21. Bellomo R, Goldsmith D, Uchino S, Buckmaster J, Hart G, Opdam $\mathrm{H}$, et al. A prospective before-and-after trial of a medical emergency team. Med J Aust 2003;179:283-7.

22. Berlot G, Pangher A, Pettrucci L, Bussani R, Lucangelo U. Anticipating events of in-hospital cardiac arrests. Eur J Emerg Med 2004;11:24-8.

23. Buist M, Bernard S, Nguyen TV, Moore G, Anderson J. Association between clinically abnormal observations and subsequent in-hospital mortality: a prospective study. Resuscitation 2004;62(2):137-41.

24. Considine J, Thomas S, Potter R. Predictors of critical care admission in emergency department patients triaged as low to moderate urgency. J Adv Nurs 2009;65(4):818-27.

25. Goldhill DR, MCNarry AF. Physiological abnormalities in early warning scores are related to mortality in adult inpatients. $\mathrm{Br}$ $J$ Anaes 2004;92(6):822-4.

26. Skrifvars M, Nurmi J, Ikola K, Saarinen K, Caster M. Reduced survival following resuscitation in patients with documented clinically abnormal observations prior to in-hospital cardiac arrest. Resuscitation 2006;70(2):215-22.

27. Connolly AM, Katz VL, Bash KL, MCMahon MJ, Hansen WF. Trauma and pregnancy. Am J Perinatol 1997;14(6):331-6.

28. van der Wulp I, van Stel HF. Calculating kappas from adjusted data improved the comparability of the reliability of triage systems: a comparative study. J Clin Epidemiol 2010;63(11):1256-63.

29. Travers DA, Waller AE, Bowling JM, Flowers D, Tintinalli J. Fivelevel triage system more effective than three-level in tertiary emergency department. J Emerg Nurs: JEN: Off Publ Emerg Dept Nurses Assoc 2002;28(5):395-400.

30. Hoffman JR, Wolfson AB, Todd K, Mower WR. Selective cervical spine radiography in blunt trauma: methodology of the national emergency X-radiography utilization study (NEXUS). Ann Emerg Med 1998;32(4):461-9.

31. Stiell IG, Wells GA, Vandemheen KL, Clement CM, Lesiuk H, De Maio VJ, et al. The Canadian C-spine rule for radiography in alert and stable trauma patients. JAMA 2001;286(15): 1841-8.

32. Bandiera G, Stiell IG, Wells GA, Clement C, De Maio V, Vandemheen $\mathrm{KL}$, et al. The Canadian C-spine rule performs better than unstructured physician judgment. Ann Emerg Med 2003;42(3):395-402.

33. Stiell IG, Greenberg GH, McKnight RD, Wells GA. Ottawa ankle rules for radiography of acute injuries. $N$ Z Med $J$ 1995;108(996): 111.

34. Stiell IG, Greenberg GH, McKnight RD, Nair RC, McDowell I, Reardon $M$, et al. Decision rules for the use of radiography in acute ankle injuries. Refinement and prospective validation. JAMA 1993;269(9):1127-32.

35. Stiell IG, Greenberg GH, McKnight RD, Nair RC, McDowell I, Worthington JR. A study to develop clinical decision rules for the use of radiography in acute ankle injuries. Ann Emerg Med 1992;21(4):384-90. 